\title{
BMJ Open Young age at school entry and attention- deficit hyperactivity disorder-related symptoms during primary school: results of a prospective cohort study conducted at German Rudolf Steiner Schools
}

\author{
Janine Wendt, ${ }^{1}$ Martina F Schmidt, ${ }_{1}^{1}$ Jochem König, ${ }^{1}$ Rainer Patzlaff, ${ }^{2}$ \\ Michael Huss, ${ }^{3}$ Michael S Urschitz ${ }^{1}$
}

To cite: Wendt J, Schmidt MF, König J, et al. Young age at school entry and attentiondeficit hyperactivity disorderrelated symptoms during primary school: results of a prospective cohort study conducted at German Rudolf Steiner Schools. BMJ Open 2018;8:e020820. doi:10.1136/ bmjopen-2017-020820

- Prepublication history and additional material for this paper are available online. To view these files, please visit the journal online (http://dx.doi org/10.1136/bmjopen-2017020820).

Received 1 December 2017 Revised 12 June 2018 Accepted 14 August 2018
Check for updates

(C) Author(s) (or their employer(s)) 2018. Re-use permitted under CC BY-NC. No commercial re-use. See rights and permissions. Published by BMJ.

For numbered affiliations see end of article.

Correspondence to Dr Michael S Urschitz; urschitz@uni-mainz.de

\section{ABSTRACT}

Objectives Young age at school entry (ASE) for students has been related to their impaired mental health in higher grades. To avoid the negative health consequences of young ASE, preschool examinations and individual school entry deferral for young children are routinely performed by some school authorities. We aimed to investigate whether ASE was associated with attention-deficit hyperactivity disorder (ADHD)-related symptoms in pupils attending schools using a selective school enrolment procedure.

Design Prospective open cohort study with baseline assessments at school entry and two follow-ups in the second and fourth grades.

Setting Up to 128 Rudolf Steiner Schools (Waldorf Schools) located within Germany.

Participants 0 the 3079 children from whom data were gathered in the second or fourth grade, 2671 children born between 1 July 2001 and 31 October 2002 (age at baseline: mean 6.7, min 5.91, max 7.24 years, 50\% girls) were selected for analysis to avoid bias introduced by individuals at the edges of the ASE distribution.

Main outcome measures ADHD-related symptoms were assessed at school entry and second and fourth grades by parent-reported and teacher-reported versions of the Strengths and Difficulties Questionnaire (HyperactivityInattention Subscale).

Results The agreement between parent-reported and teacher-reported symptoms was poor (intra-class correlation: 0.41 and 0.44 in second and fourth grade assessments, respectively). Regarding teacher reports, ASE was negatively associated with ADHD-related symptoms in the second grade (regression coefficient $\beta=-0.66$ per year, $P=0.0006)$ and fourth grade $(\beta=-0.56, P=0.0014)$. Associations remained after adjusting for potential confounders and pre-existing symptoms at baseline. Regarding parent reports, associations were markedly weaker in both grades (second grade: $\beta=-0.22, P=0.12$; fourth grade: $\beta=-0.09, P=0.48$ ).

Conclusions Using a prospective study design and comprehensive adjustment for confounding and baseline
Strengths and limitations of this study

- A prospective open cohort study including a large sample of a homogeneous population throughout Germany.

- It was possible to assess ADHD-related symptoms in a dual-setting approach (at home and in school) using a validated instrument.

- We were able to adjust for baseline symptoms at school entry from parent reports and other sociodemographic confounders.

- Adjusting for parent reports of ADHD-related symptoms prior to school entry might not have been a sufficient control for analyses involving teacher reports of $A D H D$-related symptoms at subsequent time points.

symptoms, we confirmed prior evidence of the association between young ASE and teacher-reported ADHD symptoms in primary school.

\section{INTRODUCTION}

Attention-deficit hyperactivity disorder $(\mathrm{ADHD})$ is an externalising neurodevelopmental disorder that results in inattention, impulsivity and hyperactivity. Worldwide, approximately 63 million children and adolescents suffer from ADHD. ${ }^{1}$ In school-aged children the estimated prevalence of ADHD is $5 \%$ to $7 \% .^{2-4}$ Hence, it is one of the most frequently occurring chronic mental health condition in childhood. ${ }^{56}$ There is no specific single cause for ADHD; however, gender, socio-economic status, migrant background and family form are potential risk factors. ${ }^{7}$ It has been shown that affected children are at a higher risk for further comorbidities such as 
autism spectrum disorder and communication, learning, and motor disorders as well as intellectual disability and tic disorders. ${ }^{8-10}$ Additionally, ADHD is associated with other externalising disorders such as oppositional defiant disorder and conduct disorders. ${ }^{911}$

There is evidence that the youngest children within a school class are at a disadvantage in many aspects compared with their older classmates. For example, they are less likely to be successful in sports leagues ${ }^{12}{ }^{13}$ and more likely to underperform throughout their school career. ${ }^{14-17}$ Moreover, previous studies from various countries have shown that a relatively young age at school entry (ASE) increases the probability of having ADHD-related symptoms ${ }^{18-21}$ or other psychopathology, ${ }^{22}$ of receiving a diagnosis of $\mathrm{ADHD}^{1723-28}$ or being treated with stimulant medications. ${ }^{23-32}$ The evidence is not consistent as other studies have not been able to demonstrate such associations. ${ }^{33-36}$ Some authors concluded that this lack of association may be related to the school enrolment policy applied in some countries. ${ }^{35}$ However, most studies investigated the relationship in retrospective or cross-sectional studies without adjusting for prevalent ADHD-related symptoms at school entry and other important ADHD risk factors. This may impede causal inference, which demands a clear temporal relationship between school entry and the later evolvement of symptoms.

We conducted a project that investigated the longterm associations between ASE, school readiness and individual skill levels as well as several health and educational outcomes in German Rudolf Steiner Schools (ie, the IPSUM project). Based on this project, we conducted a study to investigate the association between ASE and ADHD-related symptoms in primary school children. We hypothesised that children who are young for their grade have more ADHD-related symptoms compared with their older classmates.

\section{METHODS}

\section{Setting and study design}

Following pre-tests since 2004 and a large pilot study in 2007 (65 schools, 2883 participants), the present population-based prospective open cohort study was started in 2008 in cooperation with the German Association of Rudolf Steiner Schools. The study protocol was reviewed and approved by the ethics committee of the federal physician chamber in Frankfurt/Main (Hesse, Germany). Written informed consent was obtained from parents or legal guardians prior to study enrolment.

The study was conducted with a two-stage recruiting process: a baseline assessment at school entry (current age: 6-7 years) and two follow-up assessments during grade 2 (current age: 7-8 years) and 4 (current age: 9-10 years). In 2007, all German Rudolf Steiner Schools were contacted and informed about the project by mail and personal phone calls. Twenty-two Rudolf Steiner Schools for children with special educational needs were excluded. Of the 189 eligible schools in 2008, 88 (47\%) agreed to participate. All eligible schools were contacted again in $2010(n=193)$ and $2012(n=201)$ and allowed to join the study. Hence, the total number of participating schools increased from $104(54 \%)$ in 2010 to $123(61 \%)$ in 2012.

\section{Preschool examination and school enrolment policy}

In Rudolf Steiner Schools, school enrolment policy is based rather on the results of a mandatory preschool examination (PSE) than on fixed cut-off dates for eligibility. The PSE evaluates school readiness as a function of individual motoric, linguistic and cognitive skills. ${ }^{37}$ School entry for children classified as "not ready for school' is consequently deferred, and they enter school 1 year later. Due to this selective enrolment procedure, Rudolf Steiner Schools have lower proportions of early $(2 \%)$ and higher proportions of delayed school entries $(13 \%)$ compared with public schools in Germany $(6 \%$ and $5 \%$, respectively). ${ }^{38}$ This policy aims at outweighing the negative effects of young ASE on health and educational outcomes later in primary school.

\section{Study population and sample}

Study material (ie, study information, questionnaires and consent forms) were sent to the local school enrolment committee of the eligible schools. All parents who registered their child at one of the participating schools for school enrolment in 2008 were approached by the respective committee and written informed consent was obtained. The parents also filled a baseline questionnaire. In total 3373 children underwent the PSE, and parents of 2100 children $(62 \%)$ gave consent to participate in the study. Children who were ultimately not enrolled in the first grade were later excluded from the study. In 2010, all parents of second graders and in 2012, all parents of fourth graders were contacted and asked to participate in the follow-up assessments. Consequently, 1965 and 2741 children took part in the second and fourth grade assessments, respectively.

\section{Procedures and instruments}

The child's individual health status was investigated during preschool and in the second and fourth grades via a package of widely used and well-validated instruments also used in the German Health Interview and Examination Survey for Children and Adolescents. ${ }^{39}$ The parent-reported instruments covered general health, sleep problems, chronic health conditions, mental health problems, health-related quality of life and socioeconomic status. School-related behaviour, needs for special educational support and school outcomes were investigated in the second and fourth grades by teacher-reported questionnaires.

ADHD-related symptoms were investigated prior to school entry (only parent reports) and during the second and fourth grades (parent and teacher reports) using German versions of the Hyperactivity-Inattention Subscale of the Strengths and Difficulties Questionnaire 




Figure 1 Selection process of participants over time.

(SDQ) ${ }^{40}$ The Hyperactivity-Inattention Subscale consists of five items and covers the areas of hyperactivity, inattention and impulsivity. Each item is rated on 3-point Likerttype scale ranging from being not true $(0)$, and somewhat true (1) to certainly true (2). A score is created from the sum of responses over the full range of the Subscale, yielding values between 0 and 10 . A higher score thereby indicates more ADHD-related behaviour.

\section{Restrictions, definitions and statistical analysis}

To avoid bias introduced by children at the tails of the ASE distribution, we only included children who were participants in second or fourth grade and were born according to Rudolf Steiner Schools cut-off date (30 June 2002) or the respective 2008 federal state-specific cut-off dates (30 June 2002 to 31 December 2002 depending on the state). This restriction allowed us to exclude children who have been deferred the year before or were too young for school entry according to legal regulations. According to this age restriction, 408 children were excluded $(85 \%$ were too old), leaving a final analysis sample of 2671 children from 128 schools (figure 1).
ASE was defined as the time interval (in years) between the date of birth and the first day in school. As summer holidays differ between German federal states, first day in school was individually calculated for each child. Despite the assumptions that date of birth is a random process and that associations between ASE and health outcomes are not confounded by other factors, we set up a theoretical causal model and identified the following potential confounders which have been associated with ADHD in the past ${ }^{7}$ : gestational age at birth, family structure, socioeconomic status and migrant background. To improve causal inference, ADHD-related symptoms at baseline (available from parent reports) were used to adjust for pre-existing symptoms already present prior to school entry. Gestational age at birth (preterm vs term birth) and family structure (nuclear family vs single-parent family, foster parents or a children's home) was dichotomized. Based on the CASMIN classification (Comparative Analyses of Social Mobility in Industrial Nations), the socioeconomic status of the parents was defined using information about the highest school-leaving 
qualification (general education) and vocational education. ${ }^{41}$ The total CASMIN score ranged between 0.5 (still in education) and 7.0 (highest socioeconomic level). A migrant background was determined by using parents' information on current nationality and country of birth. Based on the definition of the German Federal Ministry of Justice and Consumer Protection, children were classified as having a migrant background if at least one of the parents had a non-German nationality or was born outside Germany.

Cronbach's alpha and intra-class correlation coefficients were calculated to assess internal consistency of the Hyperactivity-Inattention Subscale and the agreement between parent and teacher reports. We used the intraclass correlations coefficient for absolute agreement of single measurements based on a model with fixed rater and random subject effect. For the primary analysis, a multivariable linear regression analysis for correlated data with ASE as the independent variable and the Hyperactivity-Inattention Subscale score as the dependent variable was performed. Each child contributed up to four observations (parent and teacher reports from the second and fourth grades). Effect estimates $(\beta)$ and their SE were adjusted using three hierarchic adjustment sets (set 1: gender; set 2: set one plus birth status, family structure, CASMIN score and migrant background; set 3: set two plus parent-reported Hyperactivity-Inattention Subscale score obtained at school entry). This combined analysis allows for unbiased estimation in the presence of missing outcome assessments due to the open cohort design under the missing at random assumption. Missing data for confounders in adjustment set 2 were rare and were accounted for by including missingness indicator variables. For adjustment set 3 , a full multiple imputation procedure using the Monte Carlo Markov chain method (SAS procedure MI) was applied. The primary analysis was considered to be confirmatory; therefore, the level for type 1 error was set at 0.05 .

To investigate the association between ASE and clinically relevant ADHD-related symptoms, a secondary analysis was performed. For this, the Hyperactivity-Inattention Subscale score was dichotomised as either 'no indication of ADHD' (score <6) or 'indication of ADHD' (score $\geq 6$ ) by applying German population-based reference values. ${ }^{42}$ Associations with this binary outcome were investigated using marginal logistic regression analysis with generalised estimation equations by again combining assessments from teachers and parents in the second and fourth grades in one analysis. For multiple imputation, we used fully conditional specification methods, thus accounting for the binary outcome scale. ORs and their 95\% CIs were adjusted by the same variable sets as in the primary analysis. The secondary analysis was considered to be exploratory; P values were calculated only for descriptive purposes.

Finally, the association between ASE and the frequency of ADHD indications adjusted for confounders was graphically investigated by plotting model-based predicted proportions against ASE, stratified by gender, time of observation and source of information. All statistical analyses were carried out using IBM SPSS Statistics version 22 and SAS version 9.4.

\section{Sensitivity analysis}

A sensitivity analysis was carried out to examine the robustness of study findings with an alternative restriction criterion. Therefore, the sample was restricted to children who fully comply with the federal state-specific cut-off dates for school eligibility in 2008 (30 June 2002 to 31 December 2002 depending on the state). Due to this restriction, 747 children were excluded (92\% were too old), leaving a sample of 2332 children from 128 schools.

\section{Patient and public involvement}

Neither patients nor patient advisers have been involved in the design, the recruitment to or the conduct of the study. However, results will be disseminated to headmasters, school health physicians and parents of children attending German Rudolf Steiner Schools. Results will be also used to adapt and improve the preschool health examination at Rudolf Steiner Schools.

\section{RESULTS}

Of the 2671 children, 1329 were girls $(49.8 \%)$. The children had been born between 1 July 2001 and 31 October 2002. Mean ASE was 6.66 years (SD: 0.31; min: 5.91; max: 7.24), with girls being 3 weeks younger than boys on average. On their first day at school, only 15 children $(0.6 \%)$ were $<6$ years of age. On a descriptive basis, there was no association between ASE and the Hyperactivity-Inattention Subscale at baseline (correlation coefficient partialised for gender: $\mathrm{r}=-0.01, \mathrm{n}=1288$ ). Basic and demographic characteristics of study participants and the relationship with ASE are given in table 1 .

On a descriptive basis and compared with girls, the Hyperactivity-Inattention Subscale score was higher among the boys, regardless of the time of observation and source of information. Compared with parent reports, scores were also markedly higher in teacher reports, regardless of gender and time of observation. In addition, the score increased over time from baseline to the second grade and to fourth grade in parent reports. This was not observed in teacher reports. The observed percent distribution of Hyperactivity-Inattention Subscale score stratified by gender, source of information and time of observation is given in figure 2. Concerning the Hyperactivity-Inattention Subscale, Cronbach's alpha was 0.72, $0.75,0.87,0.76$ and 0.87 , at baseline, at second grade parent and teacher reports, and at fourth grade parent and teacher reports, respectively. The intra-class correlation between parent and teacher reports was 0.41 and 0.44 in second and fourth grade, respectively.

In the primary analysis, ASE was negatively associated with Hyperactivity-Inattention Subscale score, regardless of time of observation and source of information 
Table 1 Characteristics of study participants $(n=2671)$

Mean age/ SD at school

\begin{tabular}{llll} 
Characteristic & N & $\%$ & entry \\
\hline Gender & & & \\
Girls & 1329 & 49.8 & $6.63 / 0.31$ \\
Boys & 1342 & 50.2 & $6.68 / 0.30$
\end{tabular}

Age at school entry (years)

\begin{tabular}{|lrrr|}
\hline Less than 6.00 & 15 & 0.6 & $5.97 / 0.02$ \\
\hline 6.00 to 6.24 & 277 & 10.4 & $6.16 / 0.06$ \\
\hline 6.25 to 6.49 & 601 & 22.5 & $6.38 / 0.07$ \\
\hline 6.50 to 6.74 & 673 & 25.2 & $6.62 / 0.07$ \\
\hline 6.75 to 6.99 & 682 & 25.5 & $6.88 / 0.07$ \\
\hline 7.00 or older & 423 & 15.8 & $7.09 / 0.06$ \\
\hline
\end{tabular}

Family structure

$\begin{array}{llll}\text { Nuclear family } & 2022 & 75.7 & 6.65 / 0.31\end{array}$

\begin{tabular}{lrrr}
$\begin{array}{l}\text { Single-parent family, } \\
\text { foster parents, other }\end{array}$ & 632 & 23.7 & $6.66 / 0.30$ \\
\hline Missing & 17 & 0.6 & $6.57 / 0.22$
\end{tabular}

CASMIN classification

\begin{tabular}{|c|c|c|c|}
\hline Still in education/0.5 & 52 & 1.9 & $6.62 / 0.27$ \\
\hline $1 \mathrm{a} / 1.0$ & 0 & 0 & $\sim$ \\
\hline $1 \mathrm{~b} / 1.7$ & 4 & 0.1 & $6.64 / 0.33$ \\
\hline $2 \mathrm{~b} / 2.8$ & 8 & 0.3 & $6.57 / 0.30$ \\
\hline $1 c / 3.0$ & 57 & 2.1 & $6.66 / 0.30$ \\
\hline $2 a / 3.6$ & 361 & 13.5 & $6.68 / 0.31$ \\
\hline 2c-gen/3.7 & 34 & 1.3 & $6.66 / 0.31$ \\
\hline $2 c-v o c / 4.8$ & 484 & 18.1 & $6.67 / 0.31$ \\
\hline $3 a / 6.1$ & 419 & 15.7 & $6.67 / 0.30$ \\
\hline $3 \mathrm{~b} / 7.0$ & 1246 & 46.6 & $6.64 / 0.30$ \\
\hline Missing & 6 & 0.2 & $6.74 / 0.18$ \\
\hline \multicolumn{4}{|l|}{ Migrant background } \\
\hline No & 2185 & 81.8 & $6.66 / 0.31$ \\
\hline Yes & 481 & 18.0 & $6.65 / 0.31$ \\
\hline Missing & 5 & 0.2 & $6.72 / 0.19$ \\
\hline \multicolumn{4}{|l|}{ Gestational age at birth } \\
\hline Term & 1299 & 48.6 & $6.66 / 0.30$ \\
\hline Preterm & 92 & 3.4 & $6.71 / 0.27$ \\
\hline Missing* & 1393 & 48.0 & $6.65 / 0.31$ \\
\hline \multicolumn{4}{|c|}{ Hyperactivity-Inattention Subscale score at baseline } \\
\hline 0 & 358 & 13.4 & $6.66 / 0.29$ \\
\hline 1 & 269 & 10.1 & $6.66 / 0.31$ \\
\hline 2 & 235 & 8.8 & $6.67 / 0.30$ \\
\hline 3 & 178 & 6.7 & $6.68 / 0.30$ \\
\hline 4 & 131 & 4.9 & $6.69 / 0.30$ \\
\hline 5 & 76 & 2.8 & $6.60 / 0.27$ \\
\hline 6 & 23 & 0.9 & $6.70 / 0.28$ \\
\hline
\end{tabular}

Continued
Table 1 Continued

\begin{tabular}{lrrl}
\hline Characteristic & & & $\begin{array}{l}\text { Mean age/ } \\
\text { SD at school } \\
\text { entry }\end{array}$ \\
\hline 7 & N & \multicolumn{1}{c}{$\%$} & $\begin{array}{l}\text { ent } \\
8\end{array}$ \\
9 & 9 & 0.3 & $6.71 / 0.22$ \\
9 & 0.3 & $6.58 / 0.42$ \\
10 & 0 & 0.0 & $\sim$ \\
\hline Missing $^{*}$ & 0 & 0.0 & $\sim$ \\
\hline
\end{tabular}

*Due to the open cohort study design, the parental questionnaire at baseline was available for 1288 children only.

(table 2). For every 1 year increase in ASE, the score decreased between -0.09 and -0.73 score units. On a descriptive basis, the effect of ASE was higher for teacher-reported scores compared with parent-reported scores and higher in the second grade compared with the fourth grade. However, the effect of ASE for parent-reported scores did not reach statistical significance. Adjusting for confounders and baseline symptoms did not relevantly change effect sizes and ASE remained associated with the teacher-reported scores in the second and fourth grades. Differences in effect sizes for parent-reported scores and teacher-reported scores between second and fourth grades were not significant.

The frequency of ADHD indications ranged from $3.7 \%$ (girls, second grade, parent reports) to $25.0 \%$ (boys, second grade, teacher reports). Here as well, the frequency was higher among boys compared with girls and higher in teacher reports compared with parent reports. The gender-stratified, time-stratified and source-stratified model-based predicted proportions for all ages between 6 and 7 years are illustrated in figure 3 .

In accordance with the primary analysis, ASE was again negatively associated with ADHD indications, regardless of the time of observation and source of information. On a descriptive basis, the preventive effect of higher age was stronger in the second grade (OR ranged from 0.49 to 0.54 ) compared with the fourth grade (OR ranged from 0.59 to 0.91 ). Again, adjustments for confounding and baseline symptoms did not alter results in a relevant manner. ORs and their corresponding 95\% CI are shown in table 3.

\section{Sensitivity analysis}

In the sensitivity analysis, ASE was negatively associated with Hyperactivity-Inattention Subscale score too, regardless of time of observation and source of information. For every 1 year increase in ASE, the score decreased between 0.17 and 0.98 score units. Like in the primary analysis, the effect of ASE was higher for teacher-reported scores compared with parent-reported scores and higher in the second grade compared with the fourth grade. The effect of ASE on teacher-reported scores remained significant. The adjustment for parent-reported ADHD-related 


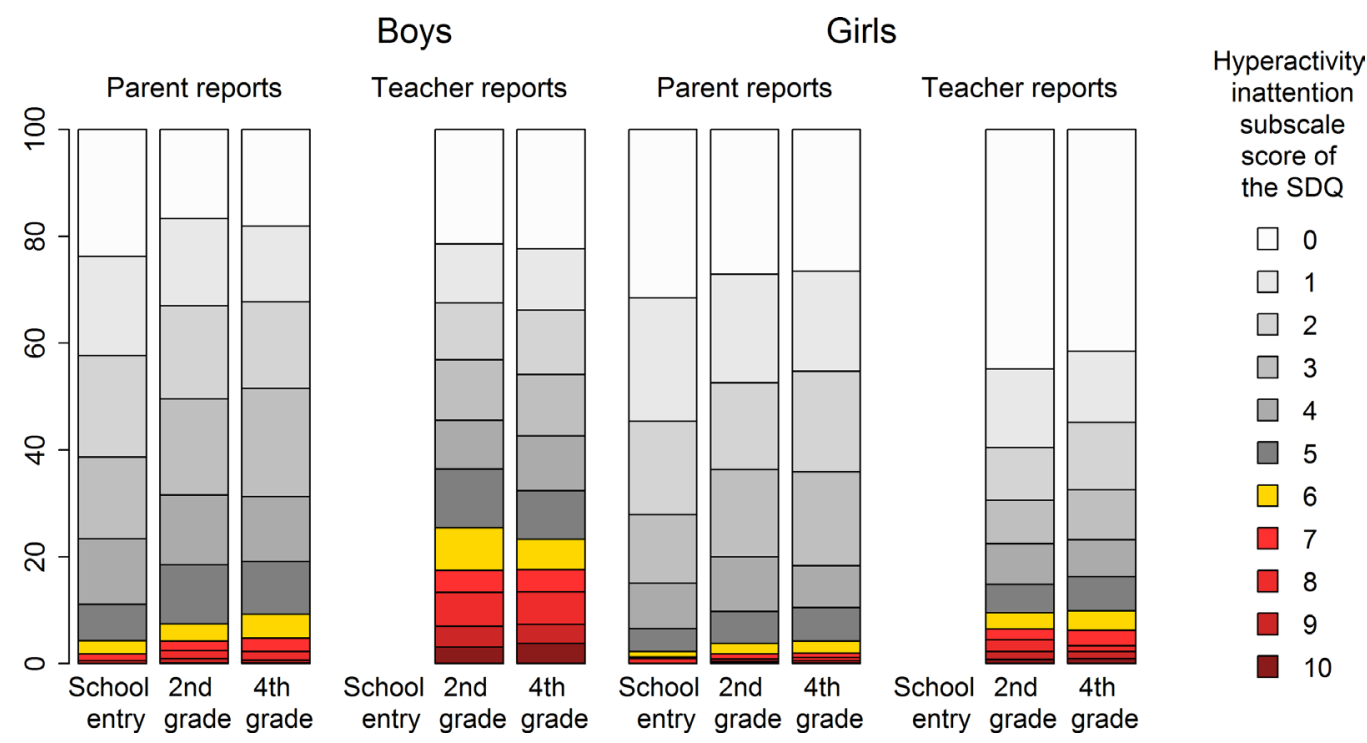

Figure 2 Observed percent distribution of Hyperactivity-Inattention Subscale score stratified by gender, time of observation and source of information. The Hyperactivity-Inattention Subscale score ranges from 0 to 10, whereby 'indication of ADHD' (borderline (6) and abnormal values (>6)) are indicated by yellow and red colours.

symptoms at baseline (set 3) yielded a significant estimate for parent reports in the second grade but not in the fourth grade. Overall, the alternative restriction criterion did not change the results considerably. All results are given in the online supplementary table 1 .

\section{DISCUSSION}

In the present study, ASE was associated with teacher-reported ADHD-related symptoms in the second and fourth grades. The association remained after adjusting for potential confounders and prevalent symptoms at school entry and was stronger in the second grade compared with the fourth grade. In contrast, we found no clear association between ASE and parent-reported ADHD-related symptoms. The strengths of the study included the homogeneous population throughout Germany, the large sample size, the dual-setting approach with symptoms assessed at home and in school, the availability of baseline symptoms at school entry and the adjustment for important confounders. However, due to particularities of the setting, the results should not be generalised to other settings or countries. To our knowledge, this is one of the few studies investigating the association in a prospective longitudinal design.

The results are consistent with previous findings from North America and Europe showing that the youngest children in class were more likely to be diagnosed and/or treated for ADHD compared with the oldest ones. ${ }^{23-26} 29$ An analysis of German administrative data showed that prevalences of both an ADHD diagnosis and ADHD medication were higher in children born immediately in the month before their designated school entry cut-off date (ie, the youngest) compared with those who were born in the month after those cut-off dates (ie, the oldest). ${ }^{28}$

In the present study, the proportion of children with ADHD indication was very high, given that in German administrative data roughly $5 \%$ of boys in second grade and $7.5 \%$ in fourth grade receive ADHD diagnosis. ${ }^{28}$ Similarly, the prevalence of an ADHD diagnosis in boys aged 7-10 reported by parents in a German representative

Table 2 Association between age at school entry and Hyperactivity-Inattention Subscale score (multivariable linear regression for correlated outcomes; $n=2671$ )

\begin{tabular}{|c|c|c|c|c|c|c|c|c|c|c|c|c|}
\hline \multicolumn{13}{|c|}{ Hyperactivity-Inattention Subscale score derived from the Strengths and Difficulties Questionnaire } \\
\hline \multirow{2}{*}{ Set } & \multicolumn{6}{|c|}{ Second grade } & \multicolumn{6}{|c|}{ Fourth grade } \\
\hline & \multicolumn{3}{|c|}{ Parent reports } & \multicolumn{3}{|c|}{ Teacher reports } & \multicolumn{3}{|c|}{ Parent reports } & \multicolumn{3}{|c|}{ Teacher reports } \\
\hline 1 & -0.22 & 0.14 & 0.1245 & -0.66 & 0.19 & 0.0006 & -0.09 & 0.13 & 0.4847 & -0.56 & 0.17 & 0.0014 \\
\hline 2 & -0.24 & 0.14 & 0.0874 & -0.68 & 0.19 & 0.0004 & -0.10 & 0.13 & 0.4251 & -0.58 & 0.17 & 0.0009 \\
\hline
\end{tabular}

Set 1: adjusted for gender.

Set 2: adjusted for set one plus birth status, family form, CASMIN score, and migrant background.

Set 3: adjusted for set two plus parent-reported Hyperactivity-Inattention Subscale score at baseline. 
Second grade

Parent reports

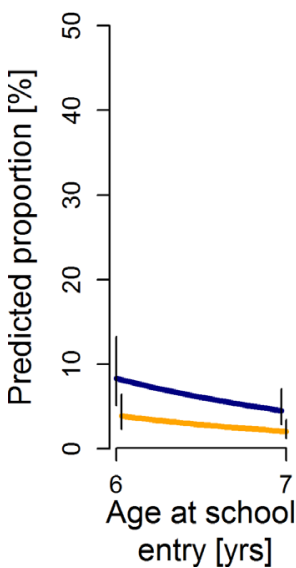

Teacher reports

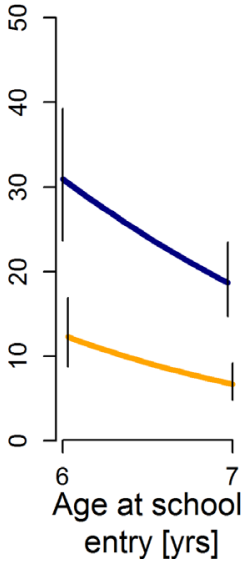

Fourth grade

Parent reports

Teacher reports

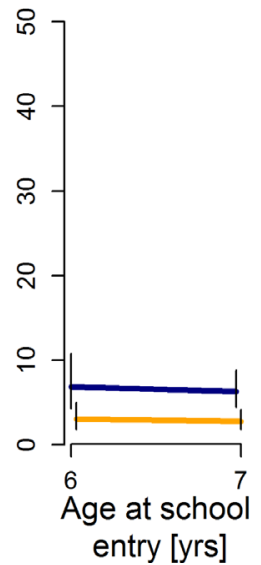

Figure 3 Frequency of predicted ADHD indication stratified by gender, time of observation and source of information. Predicted frequencies of ADHD indications are presented for boys and girls, entering school at 6 or 7 years of age, living in a nuclear family, having the highest CASMIN score and no migrant background. Vertical bars represent $95 \%$ Cls.

survey was $7.3 \%$ in 2009-2012. ${ }^{43}$ If pupils of Rudolf Steiner Schools tend to exhibit more ADHD symptoms than the general population, the results of the present study may be only carefully generalised to the entire German population.

The prospective longitudinal design of our study allowed us to adjust for differences in ADHD-related symptoms prior to school entry, which can be seen as an additional contribution to the pre-existing literature. However, it is unclear whether the longitudinal design offers methodological benefits in this specific research question. Some previous cross-sectional studies use timing of birth in narrow windows around school entry cut-off dates, which corresponds to a 'natural experiment' generating variation in age for grade. There is no obvious reason to expect differences in ADHD-related symptoms before school entry across age groups, making it probably unnecessary to adjust for these differences (or other potential confounders) as there should be none. However, we decided to empirically investigate the existence of differences across age groups rather than just to argue that differences should not exist. In the present study, the association between ASE and ADHD-related symptoms remained after controlling for baseline symptoms; in fact, the effect estimates did not change at all. Although ADHD-related symptoms at school entry were correlated with symptoms in the second and fourth grades, there was no correlation with ASE at baseline. Thus, adjusting for baseline symptoms may not be of great importance in such studies. On the other hand, baseline symptoms were only available from parent reports and not from teacher reports (and these data were used to adjust effect estimates) and were missing and imputed for more than half of the sample. In view of the poor agreement between parent and teacher reports, the sole adjustment for parent-reported symptoms might have caused bias due to insufficient adjustment. Nevertheless, it was not possible to gather teacher ratings concerning ADHD-related behaviour prior to school enrolment.

We observed a poor agreement between parent and teacher reports concerning ADHD-related symptoms. On average, the frequency of ADHD indications was twofold

Table 3 Association between age at school entry and indication of ADHD (multivariable logistic regression; $n=2671$ )

Indication of ADHD derived from the Hyperactivity-Inattention Subscale of the Strengths and Difficulties Questionnaire

\begin{tabular}{|c|c|c|c|c|c|c|c|c|c|c|c|c|}
\hline \multirow{3}{*}{ Set } & \multicolumn{6}{|c|}{ Second grade } & \multicolumn{6}{|c|}{ Fourth grade } \\
\hline & \multicolumn{3}{|c|}{ Parent reports } & \multicolumn{3}{|c|}{ Teacher reports } & \multicolumn{3}{|c|}{ Parent reports } & \multicolumn{3}{|c|}{ Teacher reports } \\
\hline & OR $^{*}$ & \multicolumn{2}{|c|}{$95 \% \mathrm{Cl}$} & OR $^{*}$ & \multicolumn{2}{|c|}{$95 \% \mathrm{Cl}$} & OR $^{*}$ & \multicolumn{2}{|c|}{$95 \% \mathrm{Cl}$} & OR $^{*}$ & \multicolumn{2}{|c|}{$95 \% \mathrm{Cl}$} \\
\hline 1 & 0.54 & 0.28 & 1.05 & 0.52 & 0.33 & 0.80 & 0.89 & 0.51 & 1.54 & 0.62 & 0.41 & 0.93 \\
\hline 2 & 0.52 & 0.27 & 1.03 & 0.51 & 0.33 & 0.80 & 0.91 & 0.52 & 1.60 & 0.61 & 0.40 & 0.92 \\
\hline
\end{tabular}

Set 1: adjusted for gender.

Set 2: adjusted for set one plus birth status, family form, CASMIN score, and migrant background.

Set 3: adjusted for set two plus Hyperactivity-Inattention Subscale score at baseline.

${ }^{*}$ ORs are unit ORs per 1 year of ASE. 
to threefold higher based on teacher ratings compared with parent ratings. This could be explained by either under-reporting of symptoms by parents and/or over-reporting by teachers or different symptom presentations at home versus at school. However, teacher-perceived ADHD symptoms at school are of great importance because they are associated with poor educational outcomes in higher grades. ${ }^{44}$ Beyond this, teachers may play a substantial role in initiating further diagnostic procedures for ADHD by advising parents to consult a paediatrician or child psychiatrist on the basis of the problematic behaviour. ${ }^{23}$

In contrast to agreement, parent and teacher reports were sufficiently correlated, which allowed for borrowing information by combining them into one model for correlated data. In general, the SDQ is a commonly used and validated screening instrument and a valid tool for discriminating cases with ADHD from those without ADHD. ${ }^{45}$ However, in the light of the fact that approximately $25 \%$ of boys in second grade were above cut-off, the SDQ may pick up other - not strictly ADHD-related - symptoms like stress or poor adaptation to school challenges. Moreover, we did not assess pre-existing or prevalent ADHD diagnoses or medication use for ADHD in this study. Hence, it is possible that children with a diagnosis of ADHD and an effective ameliorating treatment were misclassified as disease-free by the SDQ. However, this misclassification was non-differential (ie, misclassification affected children of all ages in the same way) and would not explain our findings. In fact, the association between ASE and ADHD diagnoses and/or medication has been already investigated by others and was not the primary aim of the present study.

We studied the association between ASE and ADHD-related symptoms in a particular school setting where PSEs with a focus on developmental aspects are well established and school entry deferral as an educational intervention occurs routinely. ${ }^{38}$ Also here, the negative health effects of young ASE were obviously not fully compensated for because children at risk for developing ADHD-related symptoms may be not sufficiently identified and appropriately managed, for example, by school entry deferral or transferring a child to special transitional programmes. On the other hand, it is possible that the associations of ASE and ADHD-related symptoms would be even higher if there was not a preceding PSE with a focus on developmental aspects. In contrast to our results, a large longitudinal study from Denmark including 932032 children observed no relationship between ASE and ADHD medication. The authors concluded that this lack of association may be due to either the generally low usage of ADHD medication or the common practice of deferred school entry for young children in Denmark. ${ }^{35}$ Hence, the effect of deferring school entry and other educational interventions on ADHD should be extensively evaluated in the future and comparisons between different school settings should be performed.

As mentioned before, Rudolf Steiner Schools have lower proportions of early and higher proportions of delayed school entries compared with public schools in Germany. This policy truncates the age range and reduced the fraction of 'very young' children in the source population of our sample. In contrast, our restriction aims at reducing the fraction of 'very old' children (following school entry deferral the year before), because these children have serious medical and/or educational reasons for the deferral and would have introduced bias if not excluded. Based on these particularities, we performed a sensitivity analysis with a more rigorous restriction, now excluding more children at the edges of the age distribution. However, this did not change the results of the study. Although we increased the participation proportion of schools from $47 \%$ in 2008 to $61 \%$ in 2012, we cannot claim the sample to be representative of the general population. Because characteristics of non-responding schools and non-responding children were not available, a corresponding analysis for representativeness was not possible. Notwithstanding this concern, we assume that bias by self-selection was unlikely because schools and parents were not informed about the present research question.

The precise causal pathway between ASE and ADHD-related outcomes is unknown to date. Most of the previous findings support the immaturity hypothesis within the neurodevelopmental framework of ADHD. As age is related to developmental stage, the young and therefore less 'mature' child may be unable to adequately cope with the cognitive, emotional and social challenges following school entry. The discrepancy between this 'relative immaturity' and school-related challenges may lead to stress and overtaxing, resulting in hyperactive-inattentive behaviours. Because relative immaturity is of more importance in early childhood, the effect of ASE may be more severe in countries enrolling children at a younger age. ${ }^{46}$ Moreover, young ASE is also associated with poor school performance, ${ }^{14-17}$ which could induce additional stress for children and parents. It could be speculated that ADHD affects academic achievement, and, vice versa, that poor academic achievement affects behaviour, leading to ADHD. ${ }^{29}$ In the latter case, ADHD-related symptoms would be a temporal consequence of poor achievement. This should be targeted in future studies on this topic. It is also possible that children who are young for their grade behave adequately for their age. Only when compared with their older classmates, their behaviour appears more hyperactive or impulsive and they thus receive higher ratings of ADHD-related symptoms, particularly when assessed by their teachers. As teachers are more prone to compare children within a grade than parents, this interpretation is also supported by the different findings comparing teacher and parent reports in the present and a previous US study. ${ }^{23}$ Overall, it is of high scientific relevance to identify the causal linkage between ASE and ADHD-related outcomes.

In summary, the youngest children within a school year are at an increased risk of developing ADHD-related outcomes during primary school. There is increasing 
evidence that this association represents a causal relationship. The negative health effects of ASE can also be found in school settings with a high rate of delayed school entry. ASE should be considered an important factor when children are assessed for school readiness and school entry should be deferred when indicated. Instruments and indicators are now needed for the early identification of at-risk children prone to developing ADHD later in school career.

\section{Author affiliations}

${ }^{1}$ Division of Paediatric Epidemiology, Institute of Medical Biostatistics, Epidemiology and Informatics, University Medical Centre of the Johannes Gutenberg-University, Mainz, Germany

${ }^{2}$ Institute for Pedagogy, Sensory and Media Ecology, Stuttgart, Germany ${ }^{3}$ Department of Child and Adolescent Psychiatry, University Medical Centre of the Johannes Gutenberg-University, Mainz, Germany

Acknowledgements The authors would like to thank Christian Heckmann, Claudia McKeen, Jan Vagedes, Hanns Ackermann, Uwe Zickmann and the Medical and Pedagogical Section at the Goetheanum in Dornach, Switzerland, for their expert advice and support of the project. We would also like to thank Pilar Maria UrschitzDuprat for data entry and management, and Katherine Taylor for reviewing and proofreading the manuscript. Our thanks also go to the principals and teachers of the participating schools for their support and cooperation. Last but not the least, we particularly wish to thank all the parents and children for their participation; they made this study possible.

Contributors MFS and RP initiated the IPSUM study, obtained approvals and were involved in data acquisition. MSU provided specific knowledge regarding study design, survey methods and instruments. JW and JK cleaned the data and performed the statistical analyses. MFS, MSU, JK and JW were involved in the interpretation of the results. MH was the content expert of the study. JW prepared the first draft of the manuscript. All authors critically reviewed, revised and approved the final version.

Funding The IPSUM study was funded by the Mahle Foundation, Stuttgart; the Damus Foundation, Fulda; the German Association of Waldorf Schools, Stuttgart; the Rudolf-Steiner-Fund for Scientific Research, Nürnberg; the International Federation of Waldorf Kindergartens, Stuttgart; the Society of Anthroposophical Physicians in Germany, Filderstadt; the Christophorus - Foundation, Stuttgart; the Educational Research Centre of the German Association of Waldorf Schools, Stuttgart; the Citizen and Patient Association of 'Health Active' (Gesundheit Aktiv - Bürgerund Patientenverband) Berlin; the Hausser - Foundation, Stuttgart; the Helixor Foundation, Rosenfeld; the Willy Robert Pitzer Foundation, Bad Nauheim; the Cultura Ltd., Herdecke; the Walter and Adeline Ostheimer Foundation, Zell u.A. and the Society of Evidence (Evidenzgesellschaft), Arlesheim, Switzerland.

Competing interests JW, MFS, JK, RP, MSU: none. MH: reports grants and personal fees from Medice, grants and personal fees from Engelhard Arzneimittel, grants and personal fees from Shire, grants and personal fees from Novartis and personal fees from Janssen-Cilaq during the conduct of the study; In addition, $\mathrm{MH}$ has a patent DE 10221839 B4 issued, and a patent US 20050131292 A1 issued.

Patient consent Not required.

Ethics approval The study was approved by the ethics committee of the National Physician Chamber of Hesse, Germany.

Provenance and peer review Not commissioned; externally peer reviewed.

Data sharing statement No additional data available.

Open access This is an open access article distributed in accordance with the Creative Commons Attribution Non Commercial (CC BY-NC 4.0) license, which permits others to distribute, remix, adapt, build upon this work non-commercially, and license their derivative works on different terms, provided the original work is properly cited, appropriate credit is given, any changes made indicated, and the use is non-commercial. See: http://creativecommons.org/licenses/by-nc/4.0/.

\section{REFERENCES}

1. Polanczyk GV, Salum GA, Sugaya LS, et al. Annual research review: a meta-analysis of the worldwide prevalence of mental disorders in children and adolescents. $J$ Child Psychol Psychiatry 2015:56:345-65.

2. Polanczyk G, de Lima MS, Horta BL, et al. The worldwide prevalence of ADHD: a systematic review and metaregression analysis. Am J Psychiatry 2007;164:942-8

3. Willcutt EG. The prevalence of DSM-IV attention-deficit/hyperactivity disorder: a meta-analytic review. Neurotherapeutics 2012;9:490-9.

4. Polanczyk GV, Willcutt EG, Salum GA, et al. ADHD prevalence estimates across three decades: an updated systematic review and meta-regression analysis. Int J Epidemiol 2014;43:434-42.

5. Biederman J. Attention-deficit/hyperactivity disorder: a selective overview. Biol Psychiatry 2005;57:1215-20.

6. Biederman J, Faraone SV. Attention-deficit hyperactivity disorder. Lancet 2005;366:237-48.

7. Galéra C, Côté SM, Bouvard MP, et al. Early risk factors for hyperactivity-impulsivity and inattention trajectories from age 17 months to 8 years. Arch Gen Psychiatry 2011;68:1267-75.

8. Lichtenstein $\mathrm{P}$, Carlström $\mathrm{E}$, Råstam $\mathrm{M}$, et al. The genetics of autism spectrum disorders and related neuropsychiatric disorders in childhood. Am J Psychiatry 2010;167:1357-63.

9. Jensen CM, Steinhausen HC. Comorbid mental disorders in children and adolescents with attention-deficit/hyperactivity disorder in a large nationwide study. Atten Defic Hyperact Disord 2015;7:27-38.

10. Ahuja A, Martin J, Langley $\mathrm{K}$, et al. Intellectual disability in children with attention deficit hyperactivity disorder. J Pediatr 2013;163:890-5.

11. Taylor E, Chadwick O, Heptinstall E, et al. Hyperactivity and conduct problems as risk factors for adolescent development. J Am Acad Child Adolesc Psychiatry 1996;35:1213-26.

12. Baker J, Schorer J, Cobley S. Relative age effects. Sportwissenschaft 2010;40:26-30.

13. Musch J, Grondin S. Unequal competition as an impediment to personal development: a review of the relative age effect in sport. Developmental Review 2001;21:147-67.

14. Puhani PA, Weber AM. Does the early bird catch the worm? Empir Econ 2007;32:359-86.

15. Bedard K, Dhuey E. The persistence of early childhood maturity: international evidence of long-run age effects. The Quarterly Journal of Economics 2006;121:1437-72.

16. Gold A, Duzy D, Rauch WA, et al. Relatives lebensalter und die entwicklung schulischer leistungen. Zeitschrift für Bildungsforschung 2012;2:193-208.

17. Elder TE, Lubotsky DH. Kindergarten Entrance Age and Children's Achievement: Impacts of State Policies, Family Background, and Peers. Journal of Human Resources 2009;44:641-83.

18. Mühlenweg A, Blomeyer D, Stichnoth $\mathrm{H}$, et al. Effects of age at school entry (ASE) on the development of non-cognitive skills: Evidence from psychometric data. Econ Educ Rev 2012;31:68-76.

19. Schmiedeler S, Segerer R, Schneider W. Zusammenhang zwischen Einschulungsalter und Verhaltensauffälligkeiten. Prax Kinderpsychol Kinderpsychiatr 2015;64:104-16.

20. Dee T, Sievertsen HH. The gift of time? School starting age and mental health. Cambridge, MA: National Bureau of Economic Research, 2015.

21. Gökçe S, Yazgan Y, Ayaz AB, et al. Association between age of beginning primary school and attention deficit hyperactivity disorder. $J$ Dev Behav Pediatr 2017;38:12-19.

22. Goodman R, Gledhill J, Ford T. Child psychiatric disorder and relative age within school year: cross sectional survey of large population sample. BMJ 2003;327:472.

23. Elder TE. The importance of relative standards in ADHD diagnoses: evidence based on exact birth dates. J Health Econ 2010;29:641-56.

24. Evans WN, Morrill MS, Parente ST. Measuring inappropriate medical diagnosis and treatment in survey data: The case of ADHD among school-age children. J Health Econ 2010;29:657-73.

25. Morrow RL, Garland EJ, Wright JM, et al. Influence of relative age on diagnosis and treatment of attention-deficit/hyperactivity disorder in children. CMAJ 2012;184:755-62.

26. Halldner L, Tillander A, Lundholm C, et al. Relative immaturity and ADHD: findings from nationwide registers, parent- and self-reports. $J$ Child Psychol Psychiatry 2014;55:897-904.

27. Chen MH, Lan WH, Bai YM, et al. INfluence of relative age on diagnosis and treatment of attention-deficit hyperactivity disorder in taiwanese children. J Pediatr 2016;172:162-7.

28. Schwandt $H$, Wuppermann A. The youngest get the pill: ADHD misdiagnosis in Germany, its regional correlates and international comparison. Labour Econ 2016;43:72-86.

29. Zoëga H, Valdimarsdóttir UA, Hernández-Díaz S. Age, academic performance, and stimulant prescribing for ADHD: a nationwide cohort study. Pediatrics 2012;130:1012-8. 
30. Krabbe EE, Thoutenhoofd ED, Conradi M, et al. Birth month as predictor of ADHD medication use in Dutch school classes. Eur J Spec Needs Educ 2014;29:571-8.

31. Librero J, Izquierdo-María R, García-Gil M, et al. Edad relativa de los niños en clase y tratamiento farmacológico del trastorno por déficit de atención/hiperactividad. Estudio poblacional en un departamento de salud. Medicina Clínica 2015;145:471-6.

32. Hoshen MB, Benis A, Keyes KM, et al. Stimulant use for ADHD and relative age in class among children in Israel. Pharmacoepidemiol Drug Saf 2016;25:652-60.

33. Dalsgaard S, Humlum MK, Nielsen HS, et al. Relative standards in ADHD diagnoses: the role of specialist behavior. Econ Lett 2012;117:663-5.

34. Lien L, Tambs K, Oppedal B, et al. Is relatively young age within a school year a risk factor for mental health problems and poor school performance? A population-based cross-sectional study of adolescents in Oslo, Norway. BMC Public Health 2005;5:102.

35. Pottegård A, Hallas J, Hernández -Díaz, et al. Children's relative age in class and use of medication for ADHD: a Danish Nationwide Study. J Child Psychol Psychiatry 2014;55:1244-50.

36. Biederman J, Petty CR, Fried R, et al. Is the diagnosis of ADHD influenced by time of entry to school? An examination of clinical, familial, and functional correlates in children at early and late entry points. J Atten Disord 2014;18:179-85.

37. Patzlaff R, Boeddecker D, Schmidt M. Einschulungsalter und Gesundheitsentwicklung. Ein Forschungsprojekt des IPSUMInstituts. Erziehungskunst 2006;5:531-43.

38. Statistisches Bundesamt. Schulanfänger zum Schuljahr 2008/09 nach Einschulungsart und Schulart: (Thematische Recherche: Schulanfänger: Bundesländer, Schuljahr, Geschlecht,
Einschulungsart, Schulart). Wiesbaden, 2013 www.destatis.de (accessed 12 Oct 2015).

39. Kurth BM, Kamtsiuris $\mathrm{P}, \mathrm{Hölling} \mathrm{H}$, et al. The challenge of comprehensively mapping children's health in a nation-wide health survey: design of the German KiGGS-Study. BMC Public Health 2008;8:196

40. Goodman R. The Strengths and Difficulties Questionnaire: a research note. J Child Psychol Psychiatry 1997;38:581-6.

41. Brauns H, Scherer S, Steinmann S. The CASMIN Educational Classification in International Comparative Research. In: HoffmeyerZlotnik JHP, Wolf C, eds. Advances in cross-national comparison: A European working book for demographic and socio-economic variables. New York: NY: Kluwer Acad./Plenum Publ, 2013:221-44.

42. Woerner W, Becker A, Rothenberger A. Normative data and scale properties of the German parent SDQ. Eur Child Adolesc Psychiatry 2004;13(Suppl 2):10.

43. Schlack R, Mauz E, Hebebrand J, et al. Hat die Häufigkeit elternberichteter Diagnosen einer Aufmerksamkeitsdefizit-/ Hyperaktivitätsstörung (ADHS) in Deutschland zwischen 2003-2006 und 2009-2012 zugenommen?: Ergebnisse der KiGGS-Studie Erste Folgebefragung (KiGGS Welle 1). Bundesgesundheitsblatt, Gesundheitsforschung, Gesundheitsschutz 2014;57:820-9.

44. Currie J, Stabile M. Child mental health and human capital accumulation: the case of ADHD. J Health Econ 2006;25:1094-118.

45. Algorta GP, Dodd AL, Stringaris A, et al. Diagnostic efficiency of the SDQ for parents to identify ADHD in the UK: a ROC analysis. Eur Child Adolesc Psychiatry 2016;25:949-57.

46. Berg S, Berg E. The youngest children in each school cohort are overrepresented in referrals to mental health services. J Clin Psychiatry 2014;75:530-4. 